\title{
Development and Evaluation of the Raindrop Size Distribution Parameters for the NASA Global Precipitation Measurement Mission Ground Validation Program
}

\author{
Ali TOKAY \\ Joint Center for Earth Systems Technology, University of Maryland, Baltimore County, Baltimore, and NASA Goddard \\ Space Flight Center, Greenbelt, Maryland \\ LEO PIO D'ADDERIO \\ Department of Physics and Earth Science, University of Ferrara, and Institute of Atmospheric Sciences and Climate, National \\ Research Council, Rome, Italy \\ DAVID B. WOLFF \\ Wallops Flight Facility, NASA Goddard Space Flight Center, Wallops Island, Virginia \\ WAlter A. Petersen \\ NASA Marshall Space Flight Center, Huntsville, Alabama
}

(Manuscript received 7 May 2018, in final form 1 November 2019)

\begin{abstract}
The National Aeronautics and Space Administration Global Precipitation Measurement (GPM) mission ground validation program uses dual-polarization radar moments to estimate raindrop size distribution (DSD) parameters, the mass-weighted mean drop diameter $D_{\text {mass }}$, and normalized intercept parameter $N_{W}$, to validate the GPM Core Observatory-derived DSD parameters. The disdrometer-based $D_{\text {mass }}$ and $N_{W}$ are derived through empirical relationships between $D_{\text {mass }}$ and differential reflectivity $Z_{\mathrm{DR}}$, and between $N_{W}$, reflectivity $Z_{\mathrm{H}}$, and $D_{\text {mass. }}$ This study employs large datasets collected from two-dimensional video disdrometers (2DVD) during six different field studies to derive the requisite empirical relationships. The uncertainty of the derived $D_{\text {mass }}\left(Z_{\mathrm{DR}}\right)$ relationship is evaluated through comparisons of $2 \mathrm{DVD}$-calculated and $Z_{\mathrm{DR}}$-estimated $D_{\text {mass }}$, where $Z_{\mathrm{DR}}$ is calculated directly from $2 \mathrm{DVD}$ observations. Similarly, the uncertainty of the $N_{W}\left(Z_{\mathrm{H}}, D_{\text {mass }}\right)$ relationship is evaluated through $2 \mathrm{DVD}$-calculated and $D_{\text {mass }}$ and $Z_{\mathrm{H}^{-}}$-estimated $N_{W}$, where $D_{\text {mass }}$ and $Z_{\mathrm{H}}$ are directly calculated from $2 \mathrm{DVD}$ observations. This study also presents the sensitivity of $D_{\text {mass }}\left(Z_{\mathrm{DR}}\right)$ relationships to climate regime and to disdrometer type after developing three additional $D_{\text {mass }}\left(Z_{\mathrm{DR}}\right)$ relationships from second-generation Particle Size Velocity (PARSIVEL ${ }^{2}$ ) disdrometer (P2) observations collected in the Pacific Northwest, in Iowa, and at Kwajalein Atoll in the tropical Pacific Ocean. The application of P2-derived $D_{\text {mass }}\left(Z_{\mathrm{DR}}\right)$ relationship based on precipitation in the northwestern United States to P2 observations collected over the tropical ocean resulted in the highest error among comparisons of the three datasets.
\end{abstract}

\section{Introduction}

One of four level-1 science requirements specified by the National Aeronautics and Space Administration (NASA) for rain products collected by the NASAJapan Aerospace Exploration Agency (JAXA) Global Precipitation Measurement (GPM) mission core satellite

Corresponding author: Ali Tokay, tokay@umbc.edu states that measurements from the Core Observatory shall estimate the mass-weighted mean drop diameter $D_{\text {mass }}$ of precipitation particle size distributions to within $\pm 0.5 \mathrm{~mm}$ (Skofronick-Jackson et al. 2017). Massweighted drop diameter is one of three parameters in the normalized gamma raindrop size distribution (DSD). This version of the gamma DSD has been adopted in the GPM Dual-Frequency Precipitation Radar (DPR) algorithm (Seto et al. 2013). The normalized intercept 
parameter $N_{W}$ and the shape parameter $\mu$ are the other two parameters, the latter of which is assumed constant at $\mu=2$ for the combined radar-radiometer algorithm (Grecu et al. 2016), and at $\mu=3$ for the DPR algorithm (Iguchi et al. 2017).

The parameters of the gamma DSD are often obtained from dual-polarization radar measurements following empirical relationships (Adirosi et al. 2014). The empirical relationships are derived from disdrometer measurements or simulated DSDs and have a wide range of variability due to the differences in the source of the dataset, the various physical assumptions related to the DSD, the mathematical form of the relationship as well as the natural variability of precipitation. A majority of the previous work has relied on the median volume diameter $D_{0}$ rather than $D_{\text {mass }}$ as a parameter of gamma DSD. For example, Bringi et al. (2004) derived $D_{0}$ and $N_{W}$ from horizontally polarized reflectivity $Z_{\mathrm{H}}$ and differential reflectivity $Z_{\mathrm{DR}}$ utilizing simulated size distributions with combinations of observed and equilibrium axis ratios of raindrops (Andsager et al. 1999; Beard and Chuang 1987) for S-band radar. The coefficients and mathematical form of the relationships were different for different $Z_{\mathrm{DR}}$ intervals. Brandes et al. (2004) derived a third-order polynomial $D_{0}\left(Z_{\mathrm{DR}}\right)$ relationship, which was applicable for $Z_{\mathrm{DR}}$ between 0.3 and $3 \mathrm{~dB}$. They used a two-dimensional video disdrometer (2DVD) database from NASA's Tropical Rainfall Measurement Mission field campaign in east-central Florida with a polynomial form of axis ratio-drop size relationship (Brandes et al. 2002). Cao et al. (2008) conducted a follow-up study using a different 2DVD database resulting in different coefficients for $D_{0}\left(Z_{\mathrm{DR}}\right)$ relationship.

Thurai et al. (2012) presented a case-based study where a fourth-order polynomial for $D_{0}\left(Z_{\mathrm{DR}}\right)$ relationship was derived using 2DVD observations from a widespread stratiform event in Huntsville, Alabama. Unlike the aforementioned studies, their $D_{0}\left(Z_{\mathrm{DR}}\right)$ relationship was derived for C-band radar and $D_{0}$ was expressed as a function of $Z_{\mathrm{H}}$ and $Z_{\mathrm{DR}}$ for $D_{0}$ less than $1 \mathrm{~mm}$. Thurai et al. included a derivation of $N_{W}$ from $Z_{\mathrm{H}}$ and $D_{0}$ and found a reasonable agreement between the radar-derived and disdrometer-calculated values of $D_{0}$ and $N_{W}$.

The NASA GPM ground validation team routinely processes select National Weather Service (NWS) dual-polarization radars as well as several research radars over the United States and elsewhere for each GPM core satellite overpass (Pippitt et al. 2015). The labor-intensive quality control of the radar data aims to create a high-quality dataset, known as the GPM Validation Network (VN; Schwaller and Morris 2011).
There are currently 78 radar sites in the VN: 62 continental U.S., 9 Brazilian, 2 Alaskan, and 5 tropical sites, which provide samples of widely varying precipitation regimes. The GPM Ground Validation (GV) program compares VN-derived $D_{\text {mass }}$ and $N_{W}$ with the corresponding estimates of these quantities obtained from the GPM DPR. This is done by approximately matching in space and time the scattering volumes of the spaceborne and ground-based radars.

From a ground validation point of view, disdrometer measurements represent point measurements providing distributions of gamma DSD parameters including their expected ranges, means, and standard deviations in different precipitation regimes (e.g., tropics vs midlatitudes, oceanic vs continental, topographically uniform vs orographically complex). A direct comparison of the estimates of DSD parameters between the DPR and ground-based dual-polarimetric radars relies on the upscaling of radar measurements to DPR footprint scales and the use of empirical relationships designed to estimate $D_{\text {mass }}$ and $N_{W}$ as modeled functions of radar-observed $Z_{\mathrm{DR}}$ and $Z_{\mathrm{H}}$ (D'Adderio et al. 2018).

This paper focuses exclusively on the methodology and testing employed to develop 2DVD-based parametric relationships for $D_{\text {mass }}$ and $N_{W}$ based on $Z_{\mathrm{DR}}$ and $Z_{\mathrm{H}}$. These relationships are currently used in the radar-based VN software architecture. The resulting radar-based estimates of $D_{\text {mass }}$ and $N_{W}$ can eventually be compared to the estimates of these parameters made by DPR, though this is not attempted in the current study. A separate study describes the satellite to $\mathrm{VN}$ radar network matching statistics (Petersen et al. 2020). This study also employs Particle Size Velocity (PARSIVEL) disdrometer (P2) measurements to evaluate the utility of the empirical $D_{\text {mass }}\left(Z_{\mathrm{DR}}\right)$ relationship for several climate regimes. This study is organized as follows: Section 2 summarizes the database used in this study including probability distributions of rain rate, $D_{\text {mass }}$, and $\log \left(N_{W}\right)$ derived from the 2DVD (Schönhuber et al. 2008) and P2 (LöfflerMang and Joss 2002). Section 3 describes the mathematical form of the relationships between the DSD parameters of $D_{\text {mass }}$ and $N_{W}$ and dual-polarization radar observables of $Z_{\mathrm{H}}$ and $Z_{\mathrm{DR}}$. The accuracy of these relationships is evaluated through comparison of the DSD parameters estimated by 2DVDs from three field campaigns in section 4 . Section 5 is reserved for two sensitivity studies. First, the sensitivity of the derived $D_{\text {mass }}\left(Z_{\mathrm{DR}}\right)$ relationship is tested among three sites consisting of a tropical site and two midlatitude sites. Second, the sensitivity of the $D_{\text {mass }}\left(Z_{\mathrm{DR}}\right)$ relationship to the disdrometer type is 
presented by comparing collocated 2DVD and P2 observations from two different field campaigns. Conclusions are presented in section 6 .

\section{Database}

The 2DVD was the primary instrument used in this study to derive the relationships between the radar observables and gamma DSD parameters. The datasets included four GPM field campaigns: the Midlatitude Continental Convective Clouds experiment (MC3E) (Jensen et al. 2016); the Iowa Flood Studies (IFloodS) (Seo et al. 2018); the Integrated Precipitation and Hydrology Experiment (IPHEx) (Duan et al. 2015); the Olympic Mountain Experiment (OLYMPEx) (Houze et al. 2017); and extended (longer than 1 year) data collections made at two NASA facilities: Marshall Space Flight Center, University of Alabama at Huntsville (MSFC-UAH), and NASA Goddard Space Flight Center Wallops Flight Facility (GSFC-WFF). These datasets represent a range of midlatitude meteorological regimes including midcontinental deep convection (MC3E), flood-producing frontal and mesoscale convective systems (IFloodS), warm-season Appalachian area orographic enhancements from valley to mountain (IPHEx), West Coast cold-season orographic enhancements from ocean to mountain (OLYMPEx), as well as a year-long sampling of midlatitude continental inland (MSFCUAH) and coastal mid-Atlantic region precipitation (GSFC-WFF).

The raw 2DVD output is in the form of an ASCII daily file where each row contains information on individual particles including their equivalent diameter, fall velocity, oblateness, the sampling cross section, maximum height and width, and position of the particle in both planes, as well as a time stamp in milliseconds. The standard data processing of 2DVD observations includes construction of 1-min drop counts and DSD outputs at a 0.2 -mm-diameter interval after applying a terminal fall velocity-based threshold to eliminate splash drops (Tokay et al. 2013). In this study, several additional thresholds were applied to the 2DVD datasets. The thresholds for processing any given 1-min period were set at the minimum occurrence of 100 drops and a minimum rain rate of $0.1 \mathrm{~mm} \mathrm{~h}^{-1}$ in each 1-min observation. This eliminates $16 \%-34 \%$ of the data depending on the field campaigns. To eliminate outliers, the calculated $D_{\text {mass }}$ and S-band $Z_{\mathrm{DR}}$ were limited to maximum values of $4 \mathrm{~mm}$ and $4 \mathrm{~dB}$, respectively. These two thresholds in $D_{\text {mass }}$ and $Z_{\mathrm{DR}}$ eliminated less than $1 \%$ of the data regardless of field campaign. Considering the level-1 requirements for $D_{\text {mass }}$ to be estimated within \pm 0.5 - $\mathrm{mm}$ accuracy, the uncertainty in $2 \mathrm{DVD}$ measurement capability at drop sizes below $\sim 0.5-0.7 \mathrm{~mm}$ (Tokay et al. 2013), and the intrinsic uncertainty associated with using polarimetric radar to retrieve very small drop sizes, the estimation of $D_{\text {mass }}$ was further limited to minimum value of $0.5 \mathrm{~mm}$. In that regard, Bringi et al. (2012) recognized that the statistical fluctuations in radar measurements resulted in negative values of $Z_{\mathrm{DR}}$ and $D_{0}$ was $0.45 \mathrm{~mm}$ at $Z_{\mathrm{DR}}$ of $-0.25 \mathrm{~dB}$ for $D_{0}\left(Z_{\mathrm{DR}}\right)$ relationship presented in their study. Each dataset consists of three to seven 2DVDs and the combined 2DVD dataset provided over 204300 one-minute samples (Table 1). The sample size is determined by the duration of data collection, number of instruments, and frequency of rain. Field campaigns typically last 2 months and multiple sites are required to collect a large enough sample to represent the seasonal climate of the region. The use of five and seven 2DVDs in each field campaign led to the collection of over 9400 and 8300 samples despite dry periods of a week or longer during both IPHEx, and MC3E, respectively. Abundant rainfall, on the other hand, led to the collection of over 60100 samples using only three 2DVDs during OLYMPEx. Data collection over a year at five separate 2DVD sites led to the most extensive database with over 74400 samples being collected by the GSFC-WFF network.

The P2 data collected at Kwajalein (KWAJ) atoll served as a tropical-oceanic dataset. A multiyear dataset from this site was used for a comparative study with IFloodS and OLYMPEx. All P2 data were collected at 10 -s resolution and integrated to $1 \mathrm{~min}$. Standard processing of the $\mathrm{P} 2$ data includes the same terminal fall velocity threshold as used for 2DVD to eliminate the secondary drops and the use of modeled fall velocity versus drop diameter relationship, as opposed to the measured fall velocities (Tokay et al. 2013). The total number of 1-min samples from these three sites are listed in Table 1. Coincident database when both a 2DVD and P2 were operational and reported rainfall were used to determine the sensitivity of the empirical relationships to disdrometer type for the IFloodS and OLYMPEx data discussed in section 5. Table 1 also lists the number of 2DVD and P2 instruments and the sample size for each field campaign. It should be noted that we used a subset of available P2 data from IFloodS and OLYMPEx as shown in parentheses in Table 1.

The collective DSD datasets used in this study contain a diverse population of small (less than $1 \mathrm{~mm}$ in diameter), midsize (1-3 mm in diameter) and large (larger than $3 \mathrm{~mm}$ in diameter) drops (Tokay et al. 2013). The rich OLYMPEx dataset consists of mostly small to midsize raindrops resulting in relatively low mean and maximum rain rates (Table 2). The distribution of rain 
TABLE 1. List of the field campaigns, their coordinates, duration of database, and number and sample size of the 2DVD and P2. The number of $\mathrm{P} 2$ available during field campaigns could exceed the number of units used in this study. For the comparative study between 2DVD and P2, a subset of P2 is used as shown in parentheses.

\begin{tabular}{|c|c|c|c|c|c|c|}
\hline \multirow[b]{2}{*}{ Field campaign } & \multirow[b]{2}{*}{ Coordinates } & \multirow[b]{2}{*}{ Duration } & \multicolumn{2}{|c|}{ 2DVD } & \multicolumn{2}{|r|}{$\mathrm{P} 2$} \\
\hline & & & $\begin{array}{c}\text { No. of } \\
\text { instruments }\end{array}$ & $\begin{array}{l}\text { Sample } \\
\text { size }\end{array}$ & $\begin{array}{c}\text { No. of } \\
\text { instruments }\end{array}$ & $\begin{array}{l}\text { Sample } \\
\text { size }\end{array}$ \\
\hline $\begin{array}{l}\text { Alabama-Huntsville, Alabama } \\
\text { (MSFC-UAH) }\end{array}$ & $34.7^{\circ} \mathrm{N}, 86.5^{\circ} \mathrm{W}$ & December 2009-June 2010 & 3 & 29652 & - & - \\
\hline $\begin{array}{l}\text { Iowa Flood Studies (IFloodS)- } \\
\text { Iowa City and Waterloo, Iowa }\end{array}$ & $42.1^{\circ} \mathrm{N}, 92.2^{\circ} \mathrm{W}$ & May-June 2013 & 6 & 22300 & $14(6)$ & $58462(13077)$ \\
\hline $\begin{array}{l}\text { Integrated Precipitation and } \\
\text { Hydrology Experiment } \\
\text { (IPHEx)-Ashville, } \\
\text { North Carolina }\end{array}$ & $35.3^{\circ} \mathrm{N}, 82.3^{\circ} \mathrm{W}$ & May-June 2014 & 5 & 9421 & - & - \\
\hline $\begin{array}{l}\text { Midlatitude Continental } \\
\text { Convective Clouds } \\
\text { Experiment (MC3E)—Ponca } \\
\text { City, Oklahoma }\end{array}$ & $36.6^{\circ} \mathrm{N}, 97.4^{\circ} \mathrm{W}$ & April-June 2011 & 7 & 8303 & - & - \\
\hline $\begin{array}{l}\text { Olympic Mountain Experiment } \\
\text { (OLYMPEx)_-Olympic } \\
\text { Peninsula, Washington }\end{array}$ & $47.4^{\circ} \mathrm{N}, 123.9^{\circ} \mathrm{W}$ & November 2015-January 2016 & 3 & 60164 & $3(3)$ & 81612 (45 187) \\
\hline $\begin{array}{l}\text { Wallops Flight Facility } \\
\text { (GSFC-WFF)_-Wallops } \\
\text { Island, Virginia }\end{array}$ & $37.9^{\circ} \mathrm{N}, 75.4^{\circ} \mathrm{W}$ & August 2014-October 2015 & 5 & 74461 & - & - \\
\hline $\begin{array}{l}\text { Kwajalein Island (KWAJ)—- } \\
\text { Marshall Islands }\end{array}$ & $8.7^{\circ} \mathrm{N}, 167.7^{\circ} \mathrm{E}$ & March 2013-October 2016 & - & - & 1 & 37848 \\
\hline
\end{tabular}

intensity shows more frequent sampling of light rain (less than $1 \mathrm{~mm} \mathrm{~h}^{-1}$ ) and the least frequent of heavy rain (higher than $10 \mathrm{~mm} \mathrm{~h}^{-1}$ ) as previously observed in the literature (Tokay et al. 2002, 2013). Cumulative distributions of rain occurrence measured by the 2DVD indicate that heavy rain occurred less than $5 \%$ of the time at all six sites, while the ratio of the occurrence of light to moderate rain $\left(1-10 \mathrm{~mm} \mathrm{~h}^{-1}\right)$ varied from site to site (Fig. 1a). The ratio compares the occurrence of light versus moderate rain such that the higher the ratio is the most frequent light rain occurs. The ratio was the highest at GSFC-WFF and the lowest at MC3E. The median rain rates were also the lowest and the highest at GSFCWFF and MC3E, respectively (Table 2).

The mass-weighted mean drop diameter is often used as a defining characteristic of the DSD. For example, the presence of a large number of small drops and a relative lack of large drops will result in a lower $D_{\text {mass }}$ for a given reflectivity (Tokay et al. 2008). Considering the DSD database examined in this study, we selected $D_{\text {mass }}$ of $1.2 \mathrm{~mm}$ (Fig. 1b) as a threshold to illustrate DSDs characterized by small versus large drops. The corresponding median values of the $D_{\text {mass }}$ observed in each field data collection then reflected the dominance of

TABLE 2. Mean, median, and maximum of rain rate $R$, mass-weighted drop diameter $D_{\text {mass }}$, and logarithmic normalized intercept parameter $\log \left(N_{W}\right)$ for six different 2DVD and three different $\mathrm{P} 2$ datasets that were used in this study.

\begin{tabular}{|c|c|c|c|c|c|c|c|c|c|}
\hline & \multicolumn{3}{|c|}{$R\left(\mathrm{~mm} \mathrm{~h}^{-1}\right)$} & \multicolumn{3}{|c|}{$D_{\text {mass }}(\mathrm{mm})$} & \multicolumn{3}{|c|}{$\log \left(N_{W}\right)$} \\
\hline & Mean & Median & Max & Mean & Median & Max & Mean & Median & Max \\
\hline \multicolumn{10}{|l|}{ 2DVD } \\
\hline MSFC-UAH & 3.67 & 1.68 & 187.5 & 1.28 & 1.23 & 3.99 & 3.86 & 3.56 & 5.39 \\
\hline IFloodS & 3.37 & 1.55 & 241.6 & 1.35 & 1.28 & 3.94 & 3.84 & 3.44 & 5.46 \\
\hline IPHEx & 4.42 & 1.37 & 201.6 & 1.29 & 1.22 & 3.96 & 3.76 & 3.53 & 5.19 \\
\hline MC3E & 2.95 & 1.71 & 92.8 & 1.47 & 1.44 & 3.99 & 3.66 & 3.23 & 5.40 \\
\hline OLYMPEx & 2.54 & 1.54 & 87.1 & 1.14 & 1.11 & 3.67 & 4.02 & 3.73 & 5.50 \\
\hline GSFC-WFF & 2.55 & 0.97 & 171.2 & 1.16 & 1.10 & 3.99 & 3.90 & 3.52 & 5.68 \\
\hline \multicolumn{10}{|l|}{ PARSIVEL } \\
\hline IFloodS & 3.82 & 1.88 & 192.94 & 1.34 & 1.24 & 3.99 & 3.93 & 3.59 & 5.49 \\
\hline OLYMPEx & 2.72 & 1.74 & 98.23 & 1.05 & 1.02 & 3.57 & 4.27 & 3.97 & 5.53 \\
\hline KWAJ & 5.41 & 1.97 & 128.54 & 1.22 & 1.14 & 3.93 & 3.97 & 3.86 & 5.07 \\
\hline
\end{tabular}



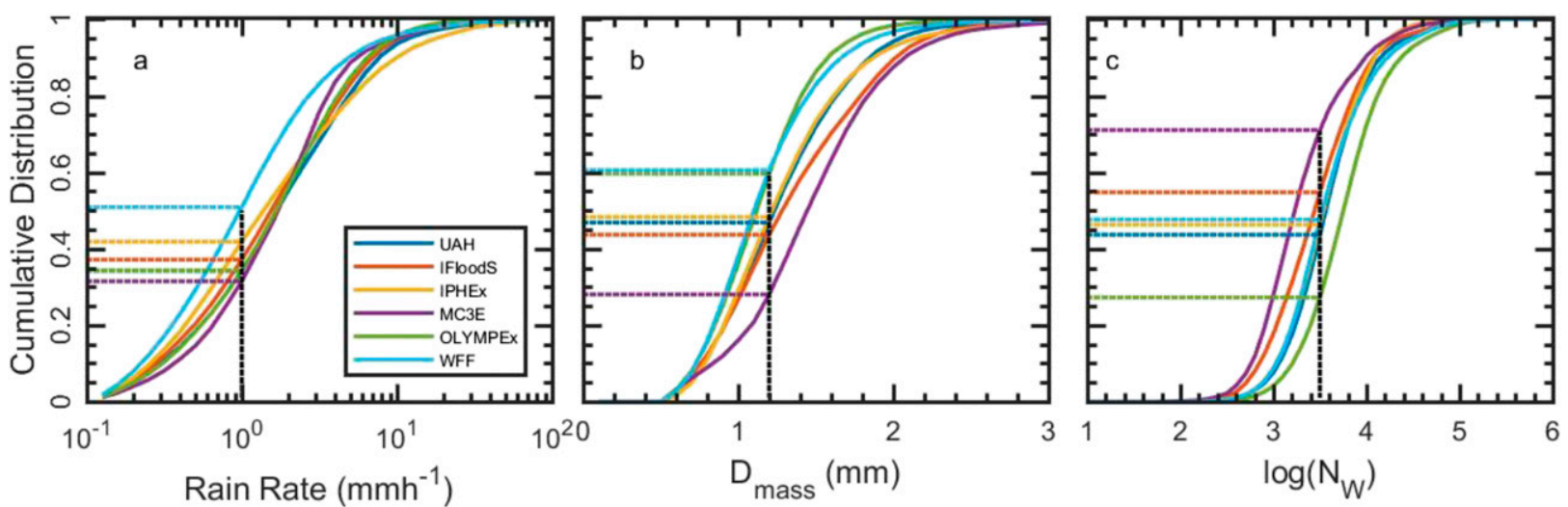

FIG. 1. Probability distributions of (a) rain rate, (b) mass-weighted drop diameter, and (c) logarithmic normalized intercept parameter of six different 2DVD datasets. The UAH and WFF sites are referred to as MSFC-UAH and GSFC-WFF in the text, respectively. The vertical dashed line represents the characteristic value of (a) rain rate $\left(1 \mathrm{~mm} \mathrm{~h}^{-1}\right)$ that separates light rain from moderate rain, (b) drop diameter $(1.2 \mathrm{~mm})$ that separates the samples of small vs medium/large drops dominance, and (c) drop count [3.5 $\left.\log \left(N_{W}\right)\right]$ that separates the samples when large number of drops were present or absent.

small drops measured in the OLYMPEx and GSFCWFF datasets, and the presence of more numerous large drops in the MC3E dataset (reflected in the ensemble statistics shown in Table 2).

The normalized intercept parameter is a function of the number of drops and its value ranges over three orders of magnitude. Because of this large variation, it is common to use the logarithmic value of $N_{W}, \log \left(N_{W}\right)$. For a given DSD, the number of small drops typically exceeds the number of middle and large drops by an order of magnitude or larger (e.g., Tokay et al. 2016, 2017). The differences in cumulative distribution of $\log \left(N_{W}\right)$ between the sites therefore reflect the presence or absence of an abundant number of small drops. Selecting $\log \left(N_{W}\right)$ of 3.5 as a threshold, MC3E and OLYMPEx received the least and the most contribution from small drops, respectively (Fig. 1c). While GSFCWFF and OLYMPEx had nearly identical cumulative distributions of $D_{\text {mass }}$, they were drastically different for the cumulative distributions of $\log \left(N_{W}\right)$. The presence of an abundant supply of small drops due to orographic enhancement played a key role on high $\log \left(N_{W}\right)$ during OLYMPEx (Zagrodnik et al. 2018). The median value of $\log \left(N_{W}\right)$ was therefore the highest during OLYMPEx compared to the other five field campaigns (Table 2).

Precipitation in the tropics forms primarily over the oceans and is characterized by the presence of a large number of small drops (Thompson et al. 2015). Thompson et al. presented the statistics of $D_{0}$ and $\log \left(N_{W}\right)$ derived from 2DVD observations from Gan and Manus Islands located in the Indian and western Pacific Oceans, respectively. Their $D_{0}$ and $\log \left(N_{W}\right)$ statistics were in a good agreement with KWAJ P2 statistics despite the differences in disdrometer type.
The median values of $D_{\text {mass }}$ and $\log \left(N_{W}\right)$ that were observed by the KWAJ P2 were low and high, respectively, relative to the values observed during IFloodS (Table 2).

The cumulative distributions of $\mathrm{P} 2$-based rain rates showed that about $35 \%$ of the observations fell into the light rain category at all $\mathrm{P} 2$ sites but heavy rain contributed nearly $8 \%$ to the observation at KWAJ (Fig. 2a). The ratio of light to moderate rain was therefore relatively higher in KWAJ than at the two midlatitude sites OLYMPEx, and IFloodS. An interesting feature was that the OLYMPEx median $D_{\text {mass }}$ was lower and median $\log \left(N_{W}\right)$ was higher than the values at KWAJ. The storms at both sites originated primarily over ocean but orographic enhancement resulted in a substantially higher number of small drops during OLYMPEx (Figs. 2b,c).

\section{Methodology}

As stated earlier, the GPM DPR algorithm adopted the normalized gamma distribution (Seto et al. 2013) as follows:

$N(D)=N_{W} f(\mu)\left(\frac{D}{D_{\text {mass }}}\right)^{\mu} \exp \left[-(4+\mu) \frac{D}{D_{\text {mass }}}\right]$

where $D$ is the equivalent volume diameter in $\mathrm{mm}$ and $f(\mu)$ is given as a function of the shape parameter $\mu$ :

$$
f(\mu)=\frac{6}{256} \frac{(4+\mu)^{4+\mu}}{\Gamma(4+\mu)},
$$

where $\Gamma$ refers to the complete gamma function. The shape parameter (unitless), $D_{\text {mass }}(\mathrm{mm})$ and $N_{W}\left(\mathrm{~mm}^{-1} \mathrm{~m}^{-3}\right)$ are 

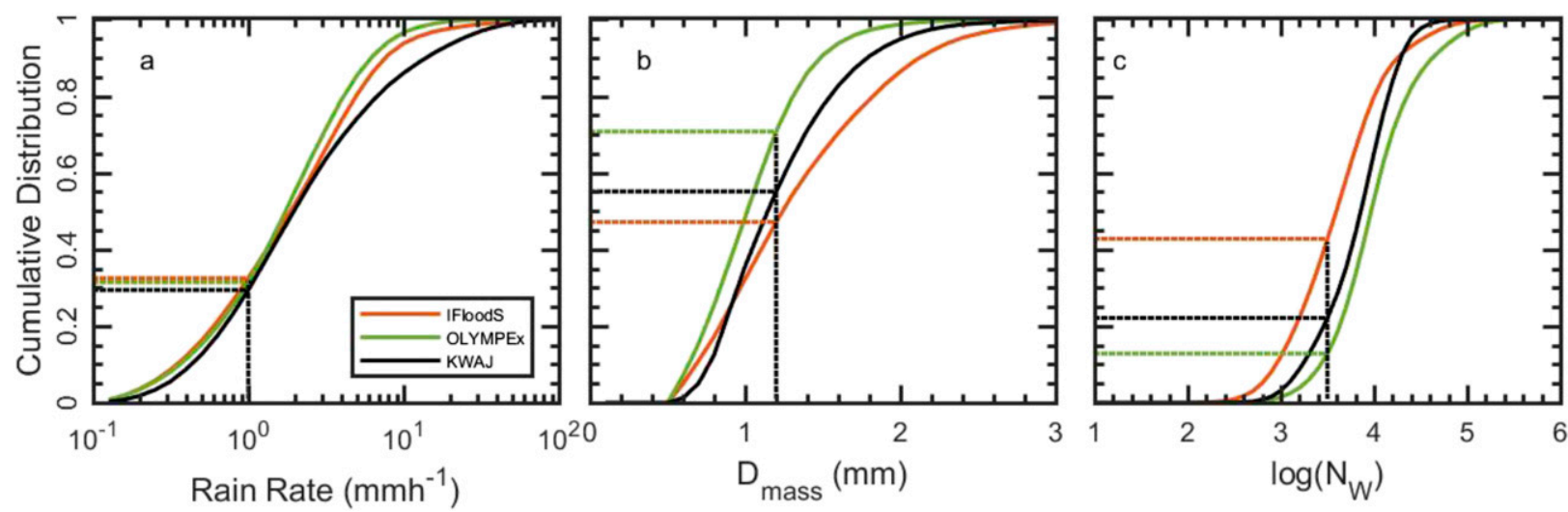

FIG. 2. Cumulative distributions of (a) rain rate, (b) mass-weighted drop diameter, and (c) logarithmic normalized intercept parameter of three different $\mathrm{P} 2$ datasets. The vertical dashed lines are as in Fig. 1.

the three parameters of the normalized gamma distribution. The mass-weighted mean drop diameter is the ratio of the fourth moment to the third moment of the size distribution, while the normalized intercept parameter is related to the liquid water content $W\left(\mathrm{~g} \mathrm{~m}^{-3}\right)$ and $D_{\text {mass }}$ and is given as

$$
N_{W}=\frac{4^{4} 10^{3} W}{\pi \rho_{W} D_{\text {mass }}^{4}},
$$

where $\rho_{w}$ is the density of water $\left(\mathrm{g} \mathrm{cm}^{-3}\right)$. Both Eqs. (1) and (3) are based on the complete gamma function where the minimum and maximum drop sizes are assumed zero and infinity, respectively. In reality, the minimum and maximum diameter are determined by what is observed during the sampling period. The incomplete gamma function accounts for the observed minimum and maximum drop size and is therefore more realistic than the complete gamma function. The complete gamma function is subject to errors in calculating rain parameters especially when the maximum drop diameter is less than $3 \mathrm{~mm}$ in diameter (Adirosi et al. 2015).

In this study, both DSD parameters $\left(D_{\text {mass }}\right.$ and $\left.N_{W}\right)$ and radar observables $\left(Z_{\mathrm{H}}\right.$ and $\left.Z_{\mathrm{DR}}\right)$ are directly calculated from disdrometer measurements. Differential reflectivity is the ratio of reflectivity at horizontal polarization $Z_{\mathrm{H}}$ to reflectivity at vertical polarization $Z_{\mathrm{V}}$. The horizontally and vertically polarized radar reflectivities, $Z_{\mathrm{H}, \mathrm{V}}$, in the Rayleigh regime are expressed as a function of the shape factors, $S_{\mathrm{H}, \mathrm{V}}$, and multiplicative factors equal to the sixth moment of the drop diameter and the number concentration $N(D)$ :

$$
Z_{\mathrm{H}, \mathrm{V}}=\int_{D_{\min }}^{D_{\max }} S_{\mathrm{H}, \mathrm{V}}(r, m) D^{6} N(D) d D .
$$

The shape factors are functions of the refractive index of water $m$ and the axis ratio $r$ of the raindrops and both refractive index and axis ratio are unitless. This study used the measured axis ratios of Andsager et al. (1999) for drops up to $6 \mathrm{~mm}$ and equilibrium drop shapes (Beard and Chuang 1987) for drops larger than $6 \mathrm{~mm}$. $Z_{\mathrm{H}, \mathrm{V}}$ and $Z_{\mathrm{DR}}$ are derived for S-band wavelength following Rayleigh-Gans theory (Seliga and Bringi 1976). In Eq. (4), $Z_{\mathrm{H}, \mathrm{V}}$ is expressed in linear units of $\mathrm{mm}^{6} \mathrm{~m}^{-3}$ but it is also used in logarithmic units of decibels $\mathrm{dBZ}$; $Z_{\mathrm{DR}}$, on the other hand, is always expressed in logarithmic units $(\mathrm{dB})$ and is given by

$$
Z_{\mathrm{DR}}=10 \log _{10}\left(\frac{Z_{\mathrm{H}}}{Z_{\mathrm{V}}}\right)
$$

where $Z_{\mathrm{H}, \mathrm{v}}$ are in linear units. A third-order polynomial with sequential intensity filtering technique (SIFT; Lee and Zawadski 2005) was employed to derive the $D_{\text {mass }}\left(Z_{\mathrm{DR}}\right)$ relationship as follows:

$$
D_{\text {mass }}=a Z_{\mathrm{DR}}^{3}+b Z_{\mathrm{DR}}^{2}+c Z_{\mathrm{DR}}+d,
$$

where $Z_{\mathrm{DR}}$ units are $\mathrm{dB}$ and where the coefficients $a, b$, $c$, and $d$, are listed in Table 3 for each of the six different datasets and the combined dataset. Polynomials represent the observations better than power-law relationships when the observations have a large scatter of the retrieved parameter ( $D_{\text {mass }}$ in this case) for a given observed parameter $\left(Z_{\mathrm{DR}}\right.$ in this case). The uncertainty in the relationship has been evaluated by calculating bias and absolute bias between the fitted and observed data. A comparative study of fourth- and third-order polynomial $D_{\text {mass }}\left(Z_{\mathrm{DR}}\right)$ relationships showed that there is insignificant improvement for the higher-order polynomial over the range of $Z_{\mathrm{DR}}$ and $D_{\text {mass }}$ values considered.

The linear least squares method is weighted to the regions where the highest percentage of data occur. For rainfall, the highest number of cases occur in light rain (rain rate $<1 \mathrm{~mm} \mathrm{~h}^{-1}$ ), which mostly corresponds to 
TABLE 3. The coefficients of the $D_{\text {mass }}\left(Z_{\mathrm{DR}}\right)$ relationship and their valid maximum $Z_{\mathrm{DR}}$ range for the six different $2 \mathrm{DVD}$ datasets and the combined dataset.

\begin{tabular}{lccccc}
\hline \hline & & & & & \multicolumn{2}{c}{ Max } \\
Field campaign & $a$ & $B$ & $c$ & $d$ & $Z_{\mathrm{DR}}(\mathrm{dB})$ \\
\hline MSFC-UAH & 0.0782 & -0.4679 & 1.5355 & 0.6377 & 3.1 \\
IFloodS & 0.1988 & -1.0747 & 2.3786 & 0.3623 & 3.1 \\
IPHEx & 0.1887 & -1.0024 & 2.3153 & 0.3834 & 2.9 \\
MC3E & 0.1861 & -1.0453 & 2.3804 & 0.3561 & 3.1 \\
OLYMPEx & 0.2209 & -1.1577 & 2.3162 & 0.3486 & 2.7 \\
GSFC-WFF & 0.0990 & -0.6141 & 1.8364 & 0.4559 & 3.5 \\
ALL & 0.0138 & -0.1696 & 1.1592 & 0.7215 & 4.0 \\
\hline
\end{tabular}

$D_{\text {mass }} \leq 1.0 \mathrm{~mm}$ and $Z_{\mathrm{DR}} \leq 0.5 \mathrm{~dB}$. Higher biases due to reduced sample numbers are expected for the population of heavy rain $\left(>10 \mathrm{~mm} \mathrm{~h}^{-1}\right)$ samples, which corresponds to high $Z_{\mathrm{DR}}$ and $D_{\text {mass }}$ values. A nonlinear least squares fit, on the other hand, is weighted toward the less frequently sampled heavy rain and causes high biases for the low rain rates samples (Tokay et al. 2001). The SIFT method is used to mitigate these sensitivities to both light and heavy rain. In SIFT, the mean values of the retrieved variable are first calculated for a prescribed interval of the observed variable. This study used an interval of $0.1 \mathrm{~dB}$ for $Z_{\mathrm{DR}}$ and the mean values of $D_{\text {mass }}$ were calculated for $Z_{\mathrm{DR}}$ between 0 and $4 \mathrm{~dB}$ as long as at least 10 samples were present in a given interval. The linear least squares method was then applied to the $D_{\text {mass }}\left(Z_{\mathrm{DR}}\right)$ pairs. The mean value of the highest $Z_{\mathrm{DR}}$ bin that had sufficient samples to be included in linear squares fit is shown in Table 3 . The number of samples that were not included in determining $D_{\text {mass }}\left(Z_{\mathrm{DR}}\right)$ relationships was less than $1 \%$ in all field campaigns.

No significant differences were observed between the $D_{\text {mass }}\left(Z_{\mathrm{DR}}\right)$ relationships in the six different datasets except that $D_{\text {mass }}\left(Z_{\mathrm{DR}}\right)$ from OLYMPEx had significantly lower $D_{\text {mass }}$ for $Z_{\mathrm{DR}}$ greater than $1.5 \mathrm{~dB}$ (Fig. 3a). The differences in $D_{\text {mass }}\left(\Delta D_{\text {mass }}\right)$ observed by combining ALL campaign specific datasets into a single $D_{\text {mass }}\left(Z_{\mathrm{DR}}\right)$ relationship were therefore most significant for OLYMPEx (Fig. 3b). Here, the presence of an abundant number of small and midsize drops caused by orographic enhancement was the driving force for the differences in the $D_{\text {mass }}\left(Z_{\mathrm{DR}}\right)$ relationships. The OLYMPEx data also had the lowest $Z_{\mathrm{DR}}$ maximum for SIFT due to the absence of large drops.

Figure 4 presents the flowchart for the GPM-GV DSD retrieval algorithm, which was developed for mapping $D_{\text {mass }}$ and $\log \left(N_{W}\right)$ over the $\mathrm{VN}$. The ground-based radar $Z_{\mathrm{H}}$ and $Z_{\mathrm{DR}}$ observations are the input and minimum and maximum values of $Z_{\mathrm{DR}}, D_{\text {mass }}$, and $\log \left(N_{W}\right)$ are set to determine whether or not $D_{\text {mass }}$ and $N_{W}$ are to be set to missing. The VN processing is primarily applied to the selected NWS operational radar network and therefore employs the ALL $D_{\text {mass }}\left(Z_{\mathrm{DR}}\right)$ relationship listed in Table 3. For observations in individual field campaigns, on the other hand, campaign-specific $D_{\text {mass }}\left(Z_{\mathrm{DR}}\right)$ relationships are used up to the maximum $Z_{\mathrm{DR}}$ values listed in Table 3. For $Z_{\mathrm{DR}}$ observations exceeding those noted in Table 3, the ALL $D_{\text {mass }}\left(Z_{\mathrm{DR}}\right)$ relationship is used.

The normalized intercept parameter is calculated as a function of $Z_{\mathrm{H}}$ and $D_{\text {mass }}$ similar to the Eq. (A.21) in Bringi et al. (2004):

$$
N_{W}=\alpha Z_{\mathrm{H}} D_{\text {mass }}^{\beta},
$$

where $Z_{\mathrm{H}}$ is in $\mathrm{mm}^{6} \mathrm{~m}^{-3}, D_{\text {mass }}$ is in $\mathrm{mm}$, and $\alpha$ and $\beta$ are the empirical coefficient and exponent, respectively. Since $D_{\text {mass }}$ is expressed as a function of $Z_{\mathrm{DR}}, N_{W}$ is therefore a function of both $Z_{\mathrm{H}}$ and $Z_{\mathrm{DR}}$. The SIFT method was applied by computing mean values of $N_{W}$ and $D_{\text {mass }}$ for $1-\mathrm{dB} Z_{\mathrm{H}}$ intervals between 0 and $60 \mathrm{~dB}$, as long as 10 or more samples were present at each interval.
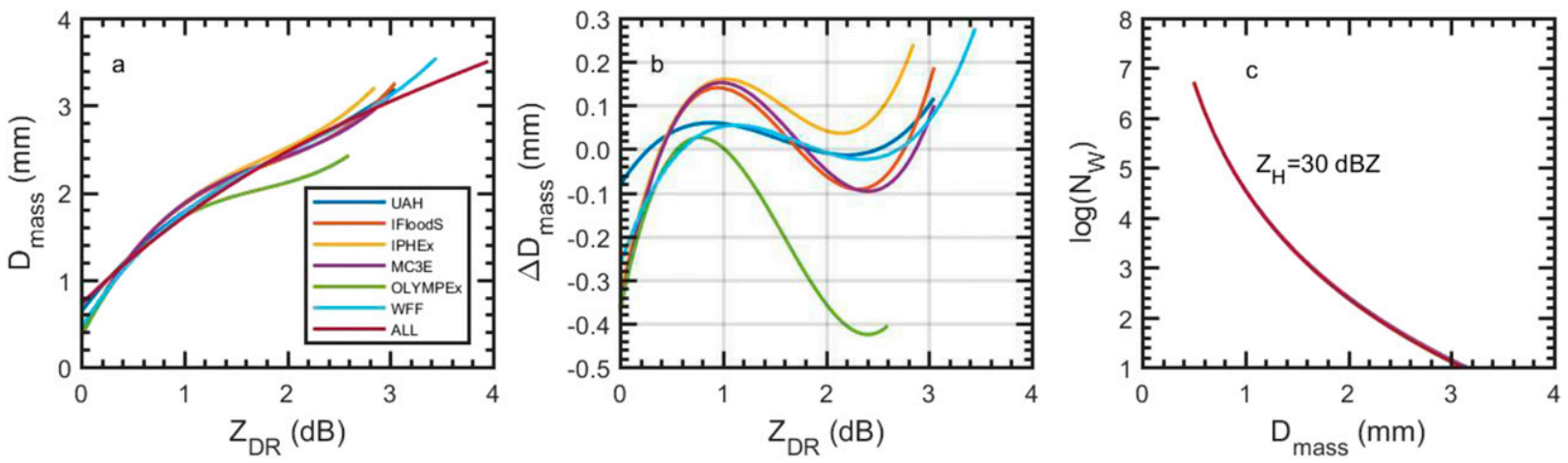

FIG. 3. (a) The $D_{\text {mass }}\left(Z_{\mathrm{DR}}\right)$ relationships for six different $2 \mathrm{DVD}$ datasets and the combined ALL dataset, (b) the difference in $D_{\text {mass }}$ between site-specific and ALL $D_{\text {mass }}\left(Z_{\mathrm{DR}}\right)$ relationship (c) $N_{W}\left(D_{\text {mass }}, Z_{\mathrm{H}}\right)$ relationships for six different $2 \mathrm{DVD}$ and ALL datasets at $Z_{\mathrm{H}}$ of $30 \mathrm{dBZ}$. The UAH and WFF sites are referred to as MSFC-UAH and GSFC-WFF in the text, respectively. 


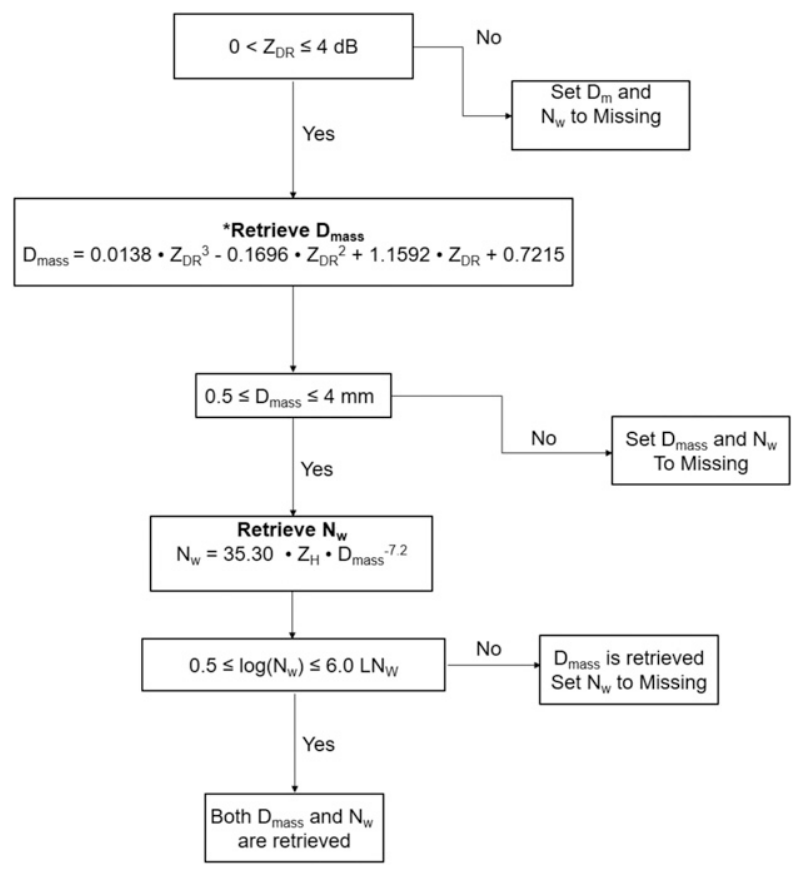

FIG. 4. A flowchart of the GPM ground validation DSD retrieval algorithm. * For $D_{\text {mass }}$, the field campaign specific $D_{\text {mass }}\left(Z_{\mathrm{DR}}\right)$ relationship is used until maximum $Z_{\mathrm{DR}}$ listed in Table 3.

The average $Z_{\mathrm{H}}$ value was converted back to linear units and linear least squares fitting was applied to the triples $\left(N_{W}, D_{\text {mass }}\right.$, and $\left.Z_{\mathrm{H}}\right)$ to obtain the coefficients $a$ and $b$ in Eq. (7). For the six datasets utilized in this study, the coefficients and exponents were nearly identical resulting in overlaid curves in $\log \left(N_{W}\right)$ versus $D_{\text {mass }}$ space at $Z_{\mathrm{H}}$ of $30 \mathrm{~dB}$ (Fig. 3c). As in the case of $D_{\text {mass }}$, the GPMGV DSD retrieval algorithm uses the ALL $N_{W}\left(Z_{\mathrm{H}}, D_{\text {mass }}\right)$ relationship, with $\alpha$ coefficient a of 35.30 and exponent $\beta$ of -7.20 . This relationship is valid for the entire $Z_{\mathrm{H}}$ range in radar observations.

The ALL $N_{W}\left(Z_{\mathrm{H}}, D_{\text {mass }}\right)$ relationship is plotted over 2DVD observations of IFloodS, IPHEx, and
OLYMPEx for $Z_{\mathrm{H}}$ between 10 and $60 \mathrm{~dB}$ (Fig. 5). The results are similar for the other four sites listed in Table 1 . Consistency between $\log \left(N_{W}\right)$ and $D_{\text {mass }}$ was evident for a given $Z_{\mathrm{H}}$ for these three field campaigns. High $\log \left(N_{W}\right)(>5)$, which generally represents the larger drop concentrations, occurred at a $Z_{\mathrm{H}}$ of $\sim 20 \mathrm{~dB}$ and $D_{\text {mass }}$ of $0.5 \mathrm{~mm}$ in all three-field campaigns. Low $\log \left(N_{W}\right)(<2)$, on the other hand, corresponded to $D_{\text {mass }}$ higher than $2.5 \mathrm{~mm}$ and $Z_{\mathrm{H}}$ greater than $35 \mathrm{~dB}$. High $D_{\text {mass }}$ values $(>3.5 \mathrm{~mm})$ corresponded to $Z_{\mathrm{H}}$ greater than $50 \mathrm{~dB}$ but the vice versa is not the true. These high $Z_{\mathrm{H}}$ values were also observed at $D_{\text {mass }}$ as low as $2 \mathrm{~mm}$ during IFloodS and IPHEx.

The inverse relationship between $\log \left(N_{W}\right)$ and $D_{\text {mass }}$ is of particular importance. When $Z_{\mathrm{DR}}$ is $0.1 \mathrm{~dB}$, small drops dominate the DSD and large drops are absent. In these cases, $D_{\text {mass }}$ can still be $0.5 \mathrm{~mm}$ or higher (Fig. 3a) but $\log \left(N_{W}\right)$ is greater than 6 at $30 \mathrm{dBZ}$ (Fig. 3c). For such a high $\log \left(N_{W}\right)$, the population of small drops should be abundant but the 2DVD observations suggest that this is an unrealistic DSD. There was not a single 2DVD observation for $\log \left(N_{W}\right)$ greater than 6 (Fig. 5). Hence it was determined that the GPM-GV DSD retrieval algorithms should eliminate noisy $Z_{\mathrm{DR}}$ samples and unphysical values of $\log \left(N_{W}\right)$ by eliminating values of $\log \left(N_{W}\right)$ below 0.5 and above 6 .

\section{Evaluation of $D_{\text {mass }}$ and $\boldsymbol{N}_{W}$ retrievals}

The accuracy of the $D_{\text {mass }}\left(Z_{\mathrm{DR}}\right)$ relationships was evaluated by comparing the $D_{\text {mass }}$ that was calculated from the 2DVDs to that retrieved from Eq. (5) employing the 2DVD-based $Z_{\mathrm{DR}}$. The field campaign specific coefficients listed in Table 3 were used to derive $D_{\text {mass }}$ from Eq. (5). Bias and absolute bias are the quantitative measures of the evaluation where bias is defined as the estimated value minus observed quantity. A negative bias therefore refers to underestimation with
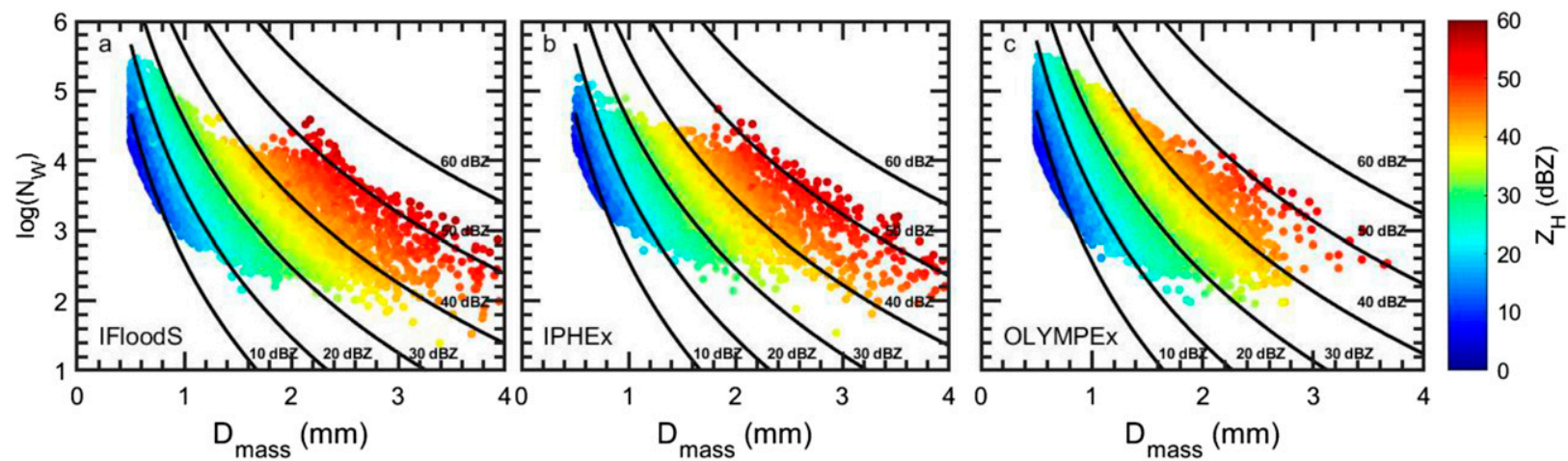

FIG. 5. ALL database $N_{W}\left(D_{\text {mass }}, Z_{\mathrm{H}}\right)$ relationship at six different $Z_{\mathrm{H}}$ ranging from 10 to $60 \mathrm{~dB} Z$ (solid lines). The 2DVD observations during (a) IFloodS, (b) IPHEx, and (c) OLYMPEx (colored circles indicate $Z_{\mathrm{H}}$ ). 

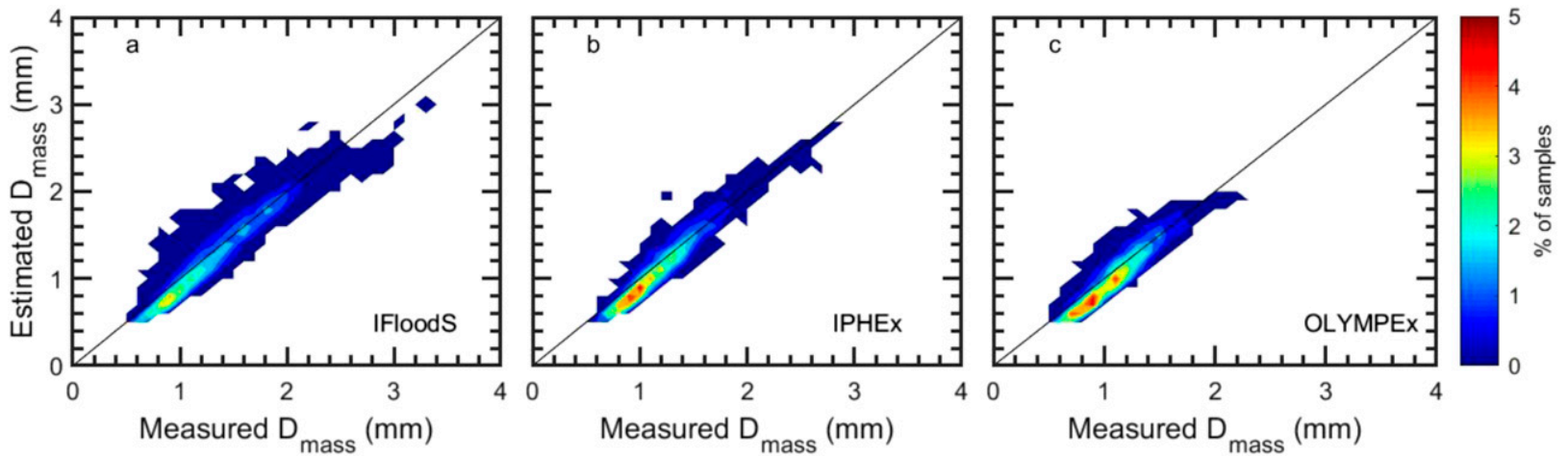

FIG. 6. A 2D density plot of measured and estimated $D_{\text {mass }}$ based on 2DVD database during (a) IFloodS, (b) IPHEx, and (c) OLYMPEx. The 2DVD-calculated $Z_{\mathrm{DR}}$ is used to estimate $D_{\text {mass }}$ following Eq. (5) and Table 3.

respect to the observed value. The $2 \mathrm{D}$ density diagram, which merges 2DVD observations in a field campaign, shows the distribution of the observations with respect to a 1:1 line. The majority of the observations fall just off the 1:1 line leaning toward measured $D_{\text {mass }}$ during IFloodS, IPHEx, and OLYMPEx (Fig. 6) as well as for MC3E, MSFC-UAH, and GSFC-WFF (not shown). This results in a very slight underestimation bias of $D_{\text {mass }}$ of $-0.07 \mathrm{~mm}$ or less (Table 4). The absolute bias, which is a measure of random error in the parametric representation, was $0.12-0.13 \mathrm{~mm}$ for $D_{\text {mass }}$, indicating that the derived $D_{\text {mass }}\left(Z_{\mathrm{DR}}\right)$ relationships represented the observed data well. Interestingly, the $\operatorname{ALL} D_{\text {mass }}\left(Z_{\mathrm{DR}}\right)$ relationship resulted in either the same or lower bias and absolute bias in $D_{\text {mass }}$ as opposed to the campaign specific $D_{\text {mass }}\left(Z_{\mathrm{DR}}\right)$ relationship during IFloodS, IPHEx, and OLYMPEx (Table 4).

The accuracy of the $N_{W}\left(Z_{\mathrm{H}}, D_{\text {mass }}\right)$ relationship was evaluated in a similar manner through comparisons of $N_{W}$, which were either directly calculated from 2DVD or retrieved from Eq. (6) using $2 \mathrm{DVD}$-based $Z_{\mathrm{H}}$ and $D_{\text {mass. }}$. Since the GPM-GV DSD retrieval algorithm uses the ALL relationship, the ALL $N_{W}\left(Z_{\mathrm{H}}, D_{\text {mass }}\right)$ relationship was used for all field campaign datasets (Fig. 7). The majority of the observations were just off the 1:1 line leaning toward estimated $\log \left(N_{W}\right)$ with a bias of equal to or less than 0.05 (Table 4). This trend was also true for the other sites, MC3E, MSFC-UAH, and GSFC-WFF (not shown). The absolute bias was $0.06-0.07$ for $\log \left(N_{W}\right)$, indicating that the $N_{W}\left(Z_{\mathrm{H}}, D_{\text {mass }}\right)$ relationships represented the observed database quite well.

\section{Sensitivity studies}

\section{a. Climate regime}

All of the 2DVD data were obtained from midlatitude sites. KWAJ $\left(8.8^{\circ} \mathrm{N}, 163.7^{\circ} \mathrm{E}\right)$, in the Marshall Islands, is a tropical oceanic site where P2 observations were available over a 3-yr period. To determine the sensitivity of the $D_{\text {mass }}\left(Z_{\mathrm{DR}}\right)$ relationship to climate regimes, P2 observations from KWAJ and two midlatitude field campaigns were employed and a $D_{\text {mass }}\left(Z_{\mathrm{DR}}\right)$ relationship was derived following the SIFT method for all four datasets. P2 also outputs precipitation phase and only rainy minutes were used in this study.

Through analysis of $\mathrm{P} 2$ data, it was seen that there were a few samples where $Z_{\mathrm{DR}}$ was high and $D_{\text {mass }}$ was low in midlatitude sites. Since the number of samples are generally low at high $Z_{\mathrm{DR}}$ values, the mean $D_{\text {mass }}$ that was calculated at high $Z_{\mathrm{DR}}$ was almost invariant with increasing $Z_{\mathrm{DR}}$ when SIFT was applied. A close look at these samples revealed that there were one or two large drops $(>4.0 \mathrm{~mm}$ in diameter) in a single or two adjacent bins with no drops in the previous four or more adjacent size bins. This was never observed in any of the 2DVD data. The fall velocities of these questionable drops were within the expected range for their sizes and there was no compelling evidence for possible dripping or two drops falling crossing the laser beam at the same time.

TABLE 4. Performance of the $D_{\text {mass }}\left(Z_{\mathrm{DR}}\right)$ and $N_{W}\left(Z_{\mathrm{H}}, D_{\text {mass }}\right)$ relationships during IFloodS, IPHEx, and OLYMPEx. Considering 2DVD-calculated $D_{\text {mass }}$ and $\log \left(N_{W}\right)$ as a reference, bias and absolute bias of these two DSD parameters were presented for the combined 2DVD dataset for each field campaign. The sample sizes were also given.

\begin{tabular}{lccc}
\hline \hline & Bias & Absolute bias & Sample size \\
\hline$D_{\text {mass }}(\mathrm{mm})$ & & & \\
$\quad$ IFloodS & -0.05 & 0.13 & 8722 \\
IPHEx & -0.05 & 0.12 & 1855 \\
OLYMPEx & -0.07 & 0.13 & 1701 \\
$\log \left(N_{W}\right)$ & & & \\
IFloodS & 0.04 & 0.06 & 8722 \\
IPHEx & 0.04 & 0.07 & 1855 \\
OLYMPEx & 0.05 & 0.06 & 1701 \\
\hline
\end{tabular}



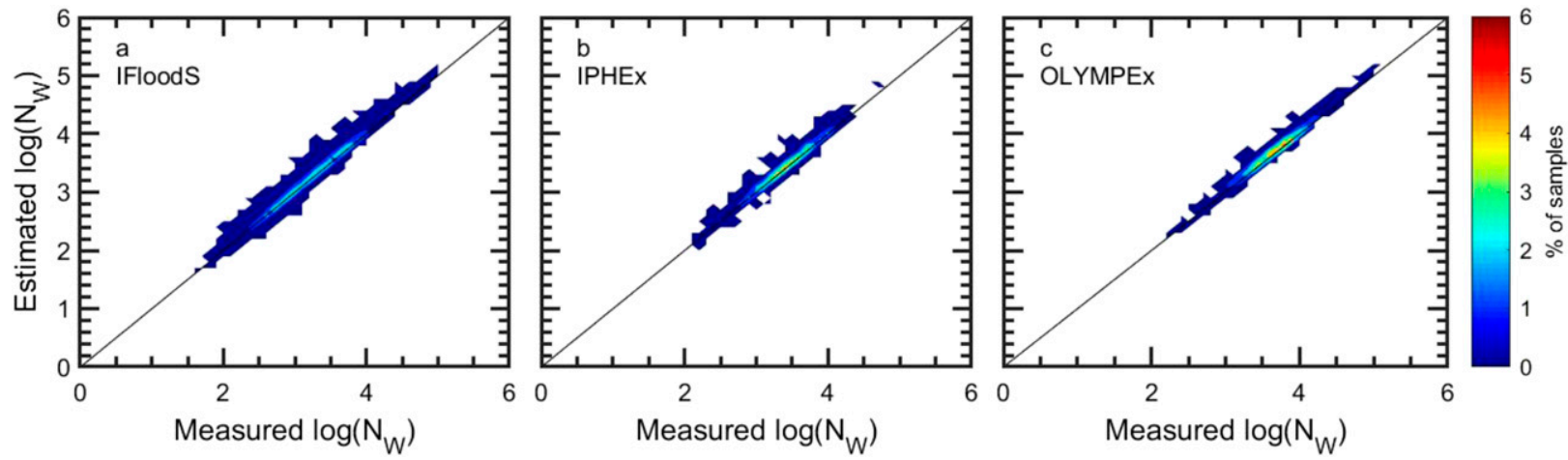

FIG. 7. A 2 D density plot of measured and estimated $\log \left(N_{W}\right)$ based on 2 DVD database during (a) IFloodS, (b) IPHEx, and (c) OLYMPEx. The 2DVD-calculated $D_{\text {mass }}$ and $Z_{\mathrm{DR}}$ are used to estimate $\log \left(N_{W}\right)$ following Eq. (6).

These suspicious drops were removed from the $\mathrm{P} 2$ database and are subject to further investigation.

The $D_{\text {mass }}\left(Z_{\mathrm{DR}}\right)$ relationship derived from IFloodS and KWAJ P2 database were in good agreement throughout the $Z_{\mathrm{DR}}$ range (Fig. 8a). Table 5 presents the coefficients of the $D_{\text {mass }}\left(Z_{\mathrm{DR}}\right)$ relationships for IFloodS, OLYMPEx, and KWAJ following Eq. (5). For $Z_{\mathrm{DR}}$ between 1 and $2 \mathrm{~dB}$, the differences in $D_{\text {mass }}$ between the IFloodS and KWAJ $D_{\text {mass }}\left(Z_{\mathrm{DR}}\right)$ relationships were only $0.04 \mathrm{~mm}$ (Fig. 8c). The IFloodS $D_{\text {mass }}\left(Z_{\mathrm{DR}}\right)$ relationship underestimated $D_{\text {mass }}$ by only $0.03 \mathrm{~mm}$ when KWAJ P2 database was used (Table 6). The absolute biases were 0.12 and $0.09 \mathrm{~mm}$ when IFloodS or KWAJ $D_{\text {mass }}\left(Z_{\mathrm{DR}}\right)$ relationships were used for IFloodS P2, and KWAJ P2 databases, respectively.

There were significant differences between OLYMPEx and KWAJ-based $D_{\text {mass }}\left(Z_{\mathrm{DR}}\right)$ relationships (Fig. $8 \mathrm{~b}$ ). The difference in $D_{\text {mass }}$ based on OLYMPEx and KWAJ $D_{\text {mass }}\left(Z_{\mathrm{DR}}\right)$ relationships increased from $0.17 \mathrm{~mm}$ at $Z_{\mathrm{DR}}$ of $1 \mathrm{~dB}$ to $0.43 \mathrm{~mm}$ at $Z_{\mathrm{DR}}$ of $2 \mathrm{~dB}$ (Fig. $8 \mathrm{c}$ ). The OLYMPEx $D_{\text {mass }}\left(Z_{\mathrm{DR}}\right)$ relationship underestimated $D_{\text {mass }}$ by $0.13 \mathrm{~mm}$ when KWAJ P2 database was used
(Table 6). The bias was also relatively high, $0.10 \mathrm{~mm}$ when KWAJ $D_{\text {mass }}\left(Z_{\mathrm{DR}}\right)$ relationship was used for OLYMPEx P2 database. The absolute biases were not drastically different when $D_{\text {mass }}\left(Z_{\mathrm{DR}}\right)$ relationship derived from one experiment was used for another experiment database. The highest absolute bias, $0.15 \mathrm{~mm}$ was observed when OLYMPEx $D_{\text {mass }}\left(Z_{\mathrm{DR}}\right)$ relationship was used for KWAJ P2 database but this was only $0.03 \mathrm{~mm}$ higher than the absolute bias when IFloodS $D_{\text {mass }}\left(Z_{\mathrm{DR}}\right)$ relationship was used for IFloodS database.

\section{b. Disdrometer type}

Before we present the analysis of the comparative study between 2DVD and P2 observations, we need to point out that both 2DVD and P2 under sample small drops less than $0.7 \mathrm{~mm}$ in diameter. In fact, the P2 manufacturer left empty the first two size bins and these two channels corresponds to the drop sizes less than $0.25 \mathrm{~mm}$. Thurai and Bringi (2018) were able to construct an accurate representation of DSD by using collocated measurements from a 2DVD and from a Meteorological
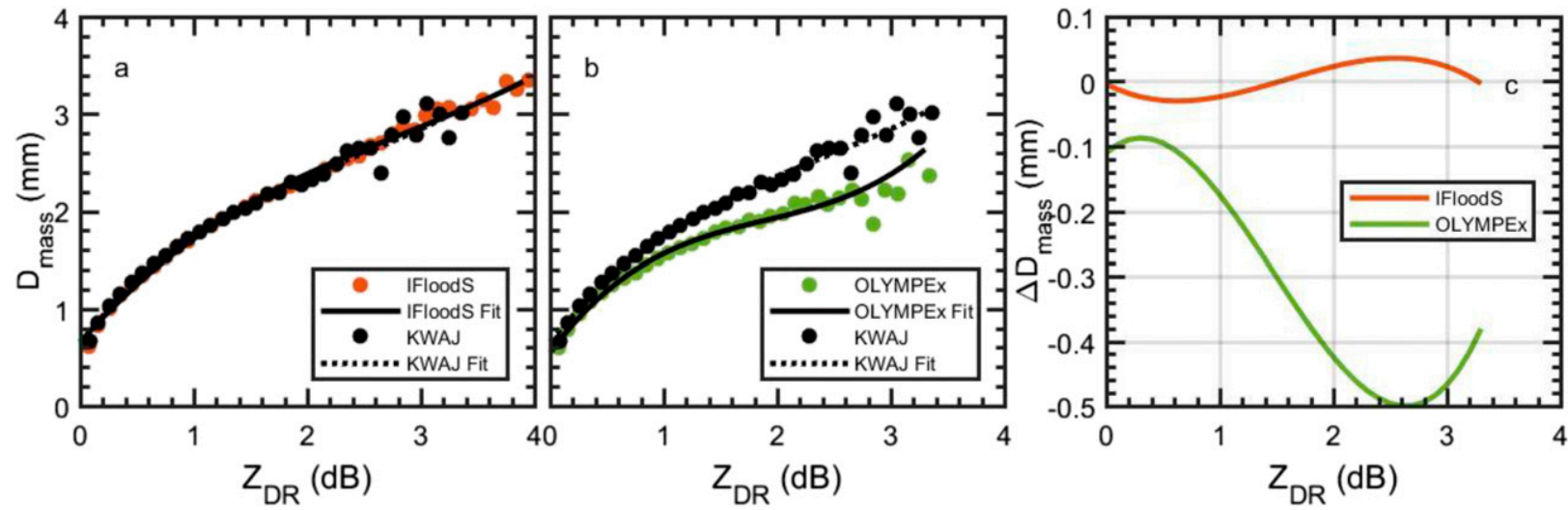

FIG. 8. Mean $D_{\text {mass }}$ for a given $Z_{\mathrm{DR}}$ interval (circles) and SIFT-based fits (lines) for (a) P2-based IFloodS and KWAJ and (b) OLYMPEx and KWAJ datasets. (c) The difference in $D_{\text {mass }}$ as a function of $Z_{\mathrm{DR}}$ based on KWAJ and IFloodS and on KWAJ and OLYMPEx $D_{\text {mass }}\left(Z_{\mathrm{DR}}\right)$ relationships. 
TABLE 5. The coefficients of the $D_{\text {mass }}\left(Z_{\mathrm{DR}}\right)$ relationship and the maximum $Z_{\mathrm{DR}}$ range for three different $\mathrm{P} 2$ datasets. The sample sizes were also given.

\begin{tabular}{lcccccc}
\hline \hline Field campaigns & $a$ & $b$ & $c$ & $d$ & Max $Z_{\text {DR }}(\mathrm{dB})$ & Sample size \\
\hline IFloodS & 0.0361 & -0.3062 & 1.3310 & 0.6561 & 3.95 & 58207 \\
OLYMPEx & 0.0187 & -0.2051 & 1.1890 & 0.6804 & 3.85 & 18512 \\
KWAJ & 0.0549 & -0.3958 & 1.4213 & 0.6601 & 3.35 & 37849 \\
\hline
\end{tabular}

Particle Spectrometer (MPS). MPS is designed to measure drizzle size drops, which are used to fill in the smalldrop portion of the DSD that is underestimated by the 2DVD.

The sensitivity of the $D_{\text {mass }}\left(Z_{\mathrm{DR}}\right)$ relationship to the disdrometer type was determined by reanalyzing the relationships for the collocated P2 and 2DVD observations from IFloodS and OLYMPEx. The subset where both disdrometers reported rainfall was employed to derive $D_{\text {mass }}\left(Z_{\mathrm{DR}}\right)$ relationships after combining all available data in each field campaign and applying the same criterion for the minimum and maximum $D_{\text {mass }}$ and $Z_{\mathrm{DR}}$ bounds. The IFloodS and OLYMPEx had six and three collocated sites, respectively, but the latter one had nearly 4.5 times more samples due to abundant rainfall (Table 7).

The agreement was good between the 2DVD- and P2-based $D_{\text {mass }}\left(Z_{\mathrm{DR}}\right)$ relationships for both field campaigns where the difference in $D_{\text {mass }}$ exceeded $0.2 \mathrm{~mm}$ only when $Z_{\mathrm{DR}}$ was greater than $1.6 \mathrm{~dB}$ for OLYMPEx and $2.6 \mathrm{~dB}$ for IFloodS (Fig. 9). The quantization of the P2 raw drop counts could partially explain the differences in $D_{\text {mass }}$ at high $Z_{\mathrm{DR}}$. To demonstrate the quantization effect, one of the OLYMPEx samples that had one drop at its twenty-first bin was considered as a test case. The midsize diameter at twenty-first bin is $5.5 \mathrm{~mm}$ with $1.0 \mathrm{~mm}$ bin width as opposed to $0.2-\mathrm{mm}$ bin width in 2DVD. The calculated $D_{\text {mass }}$ and $Z_{\mathrm{DR}}$ from $\mathrm{P} 2$ test sample were $2.43 \mathrm{~mm}$ and $2.54 \mathrm{~dB}$, respectively. If the exact size of the large drop was $5.0 \mathrm{~mm}$ (the lower edge of the bin in P2), $D_{\text {mass }}$ and $Z_{\mathrm{DR}}$ would be $2.30 \mathrm{~mm}$ and $2.41 \mathrm{~dB}$, respectively. If the drop diameter would be $6.0 \mathrm{~mm}$ (the higher end of the bin in P2), $D_{\text {mass }}$ and $Z_{\mathrm{DR}}$ were $2.66 \mathrm{~mm}$ and $2.76 \mathrm{~dB}$, respectively.

The number of samples with large drops determines the extent of the validity of the SIFT-based $D_{\text {mass }}\left(Z_{\mathrm{DR}}\right)$ relationship. Recall that a minimum of 10 samples are required to calculate mean $D_{\text {mass }}$ for a given $Z_{\mathrm{DR}}$ interval. The $\mathrm{P} 2$ registered more large drops than the 2DVD resulting in larger sample sizes of high $Z_{\mathrm{DR}}$ in both field campaigns. The maximum $Z_{\mathrm{DR}}$ interval was therefore higher for the P2 than for the 2DVD (Table 7). Quantization could play a role on the presence of more large drops in P2. Application of the P2-based $D_{\text {mass }}\left(Z_{\mathrm{DR}}\right)$ relationship on the $2 \mathrm{DVD}$ database gave underestimates of $D_{\text {mass }}$ while application of the 2DVD-based $D_{\text {mass }}\left(Z_{\mathrm{DR}}\right)$ relationship on the P2 database overestimated $D_{\text {mass }}$ (Table 8 ). For the eight different combinations in both field campaigns, the absolute bias in $D_{\text {mass }}$ was the highest, $0.13 \mathrm{~mm}$, during IFloodS when P2-based $D_{\text {mass }}\left(Z_{\mathrm{DR}}\right)$ relationship was used for 2DVD database.

\section{Conclusions}

This study presents the methodology used by the GPM ground-validation team to develop $D_{\text {mass }}\left(Z_{\mathrm{DR}}\right)$ and $N_{W}\left(Z_{\mathrm{H}}, D_{\text {mass }}\right)$ relationships for ground-based radar retrievals. The methodology is empirical and utilizes disdrometer datasets collected at six midlatitude sites and one tropical site. More emphasis was given to the retrieval of $D_{\text {mass }}$ because its accuracy is tied to the level-1 requirements of the GPM mission. The sensitivity of the $D_{\text {mass }}\left(Z_{\mathrm{DR}}\right)$ relationships to climate regime and disdrometer type was also presented. The uncertainty of the empirical relationships is shown by the twodimensional distribution histogram of the retrieved and observed variables. The empirical fits perform better for narrow and unskewed distributions of the retrieved variable for a given value of the observed variable. Considering the $D_{\text {mass }}\left(Z_{\mathrm{DR}}\right)$ relationship, the SIFT method using a third-order polynomial performed well with an absolute bias of $0.12-0.13 \mathrm{~mm}$ in $D_{\text {mass }}$ during IFloodS, IPHEx, and OLYMPEx field campaigns. The absolute bias of $\log \left(N_{W}\right)$, on the other hand,

TABLE 6 . Sensitivity of the $D_{\text {mass }}$ estimation to the climate regimes. The bias and absolute bias in $D_{\text {mass }}$ were presented when KWAJ and IFloodS (or OLYMPEx) $D_{\text {mass }}\left(Z_{\mathrm{DR}}\right)$ relationships were tested for KWAJ and IFloodS (or OLYMPEx) P2 databases.

\begin{tabular}{|c|c|c|c|c|}
\hline & $\begin{array}{l}\text { Bias } \\
(\mathrm{mm})\end{array}$ & $\begin{array}{c}\text { Absolute } \\
\text { bias }(\mathrm{mm})\end{array}$ & $\begin{array}{l}\text { Bias } \\
(\mathrm{mm})\end{array}$ & $\begin{array}{l}\text { Absolute } \\
\text { bias (mm) }\end{array}$ \\
\hline & \multicolumn{2}{|c|}{ IFloodS P2 data } & \multicolumn{2}{|c|}{ OLYMPEx P2 data } \\
\hline IFloodS/OLYMPEx & 0.00 & 0.12 & -0.01 & 0.10 \\
\hline \multirow[t]{2}{*}{ KWAJ } & 0.02 & 0.12 & 0.10 & 0.12 \\
\hline & \multicolumn{2}{|c|}{ KWAJ P2 data } & \multicolumn{2}{|c|}{ KWAJ P2 data } \\
\hline IFloodS/OLYMPEx & -0.03 & 0.09 & -0.13 & 0.15 \\
\hline KWAJ & -0.01 & 0.09 & -0.01 & 0.09 \\
\hline
\end{tabular}


TABLE 7. The coefficients of the $D_{\text {mass }}\left(Z_{\mathrm{DR}}\right)$ relationship and the maximum $Z_{\mathrm{DR}}$ range for two different $2 \mathrm{DVD}$ and $\mathrm{P} 2$ datasets, which consist of coincident observations. The sample sizes were also given.

\begin{tabular}{lccccccc}
\hline \hline Field campaign & Disdrometers & $a$ & $b$ & $c$ & $d$ & Max $Z_{\text {DR }}(\mathrm{dB})$ & Sample size \\
\hline IFloodS & 2DVD & 0.1931 & -0.9770 & 2.1130 & 0.5138 & 3.1 & 13088 \\
& P2 & 0.0312 & -0.2938 & 1.3264 & 0.6607 & 3.7 & 2.7 \\
OLYMPEx & 2DVD & 0.0430 & -0.2888 & 1.1661 & 0.7044 & 58711 \\
& P2 & 0.1194 & -0.6400 & 1.4849 & 0.5813 & 3.2 & \\
\hline
\end{tabular}

was $0.06-0.07$ for the same three field campaigns in the $N_{W}\left(Z_{\mathrm{H}}, D_{\text {mass }}\right)$ relationship.

The 2DVD database from six sites was used to derive empirical relationships in estimating $D_{\text {mass }}$ and $N_{W}$. Although all six locations were at midlatitudes, there were noticeable differences in the coefficients of the $D_{\text {mass }}\left(Z_{\mathrm{DR}}\right)$ relationships due to the differences in climate regimes. Orographic enhancement played a key role in the presence of abundant small drops and low concentrations of large drops resulting in lower $D_{\text {mass }}$ at high $Z_{\mathrm{DR}}$ during OLYMPEx in contrast to the other five sites. A few large drops resulted in large $Z_{\mathrm{DR}}$ due its sensitivity to the drop shape, while $D_{\text {mass }}$ remained relatively low due to its sensitivity to the concentration of large drops.

At KWAJ, a tropical oceanic site, large concentrations of small drops were also present while large drops were rare. The maximum $Z_{\mathrm{DR}}$ interval was therefore considerably lower at KWAJ than the two midlatitude sites in Table 5. A P2-based comparison of $D_{\text {mass }}\left(Z_{\mathrm{DR}}\right)$ relationships between KWAJ, IFloodS, and OLYMPEx revealed that the use of the OLYMPEx-based relationship for the KWAJ database resulted in the highest absolute bias, $0.15 \mathrm{~mm}$ in $D_{\text {mass }}$. The lower absolute bias in $D_{\text {mass }}$ when the IFloodS-based relationship was used for the KWAJ database did not necessarily indicate a similar size spectrum from small to large drops though. The probability distribution of $\log \left(N_{W}\right)$ in Fig. 1, for instance, showed a significant difference between IFloodS and KWAJ, which can be attributed to large number of small drops at the KWAJ site relative to the IFloodS site. Comparison between the 2DVD and P2 measurements showed that the absolute bias in $D_{\text {mass }}$ was relatively high, $0.12-0.13 \mathrm{~mm}$, when the P2-based $D_{\text {mass }}\left(Z_{\mathrm{DR}}\right)$ relationship was applied to the 2DVD databases obtained during OLYMPEx and IFloodS. The differences in $D_{\text {mass }}$ due to the differences between P2- and 2DVD-based $D_{\text {mass }}\left(Z_{\mathrm{DR}}\right)$ relationships exceeded $0.2 \mathrm{~mm}$ at $Z_{\mathrm{DR}}$ greater than 1.6 and $2.6 \mathrm{~dB}$ during OLYMPEx and IFloodS, respectively. These high $Z_{\mathrm{DR}}$ regimes receive significant contributions from large drops where the quantization due to binned P2 raw data plays a role. Although we were unable to quantify this effect, the underestimation of small drops by both 2DVD (Thurai and Bringi 2018) and P2 (Park et al. 2017) results in higher $D_{\text {mass }}$ and lower $N_{W}$ estimates than the actual values.

This study incorporated six 2DVD and three P2 datasets from seven different sites. While these sites exhibit diversity in terms of climate regime, other climate zones are worthy to expand this study further. New datasets from semiarid climate zone of southwestern United States and mountainous South Korea are becoming available and can be added to the validation of the derived $D_{\text {mass }}\left(Z_{\mathrm{DR}}\right)$ relationship presented in this study. The sensitivity of $N_{W}\left(Z_{\mathrm{H}}, D_{\text {mass }}\right)$
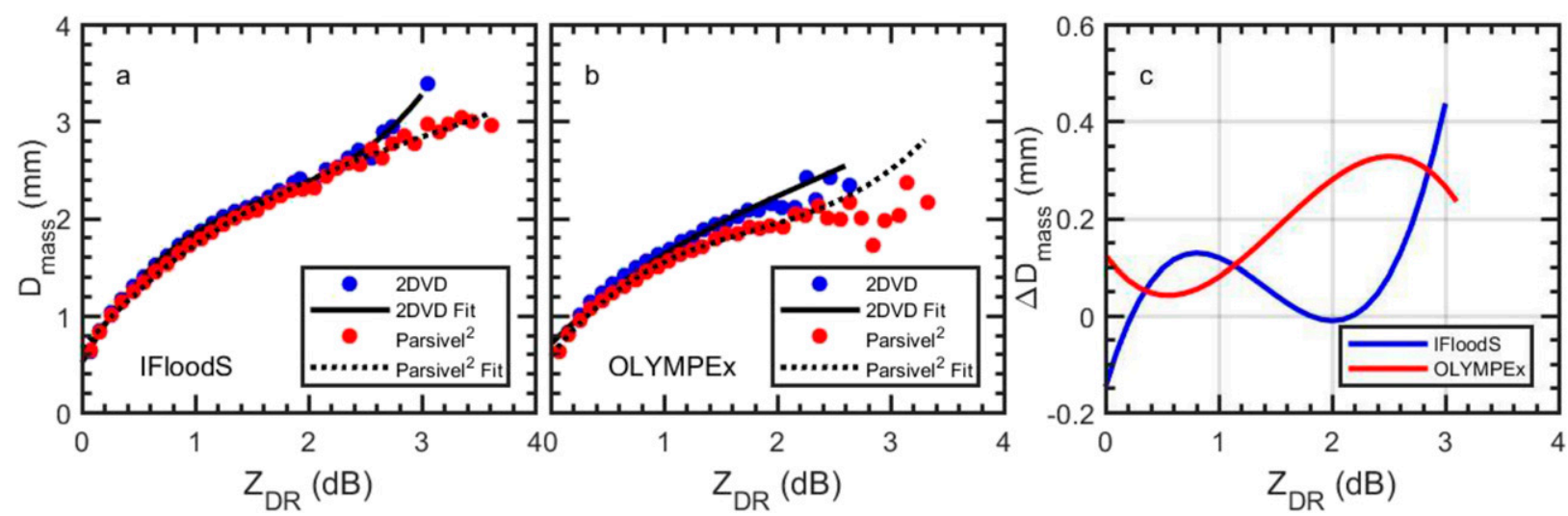

FIG. 9. Mean $D_{\text {mass }}$ for a given $Z_{\mathrm{DR}}$ interval (circles) and SIFT-based fits (lines) for 2DVD and P2 datasets during (a) IFloodS, and (b) OLYMPEx. (c) The difference in $D_{\text {mass }}$ as a function of $Z_{\mathrm{DR}}$ based on $2 \mathrm{DVD}$ - and P2-based $D_{\text {mass }}\left(Z_{\mathrm{DR}}\right)$ relationships during IFloodS and during OLYMPEx. 
TABLE 8. Sensitivity of the $D_{\text {mass }}$ estimation to the disdrometer type. The bias and absolute bias in $D_{\text {mass }}$ were presented when 2DVD and P2 $D_{\text {mass }}\left(Z_{\mathrm{DR}}\right)$ relationships were tested for both 2DVD and P2 databases during IFloodS and OLYMPEx.

\begin{tabular}{lccccc}
\hline \hline & \multicolumn{2}{c}{ IFloodS } & & \multicolumn{2}{c}{ OLYMPEx } \\
\cline { 2 - 3 } \cline { 5 - 6 } & Bias (mm) & $\begin{array}{c}\text { Absolute } \\
\text { bias (mm) }\end{array}$ & & Bias (mm) & $\begin{array}{r}\text { Absolute } \\
\text { bias (mm) }\end{array}$ \\
\hline 2DVD data & & & & & \\
2DVD & -0.01 & 0.10 & & -0.02 & 0.11 \\
P2 & -0.06 & 0.13 & & -0.08 & 0.12 \\
P2 data & & & & \\
2DVD & 0.05 & 0.11 & & 0.06 & 0.11 \\
P2 & -0.01 & 0.11 & & -0.01 & 0.10 \\
\hline
\end{tabular}

relationships to different climate zones and disdrometer type can also be considered as a future study.

This study recognized the sensitivity of $Z_{\mathrm{DR}}$ to the drop shape but did not investigate the impact of the deviations from mean drops shape in $Z_{\mathrm{DR}}$ and therefore $D_{\text {mass }}\left(Z_{\mathrm{DR}}\right)$ relationship. Gorgucci et al. (2002) derived $D_{0}\left(Z_{\mathrm{DR}}\right)$ and $D_{\text {mass }}\left(Z_{\mathrm{DR}}\right)$ relationships using the same mean axis ratio versus drop diameter relationship presented in this study but they also presented the sensitivity of the coefficients of $D_{0}\left(Z_{\mathrm{H}}, Z_{\mathrm{DR}}\right)$ relationship to the drop shape.

The empirical relationships developed herein between the VN and DPR is used for direct comparison of DSD parameters (Petersen et al. 2020). One significant aspect of the VN comparison process is the careful geographic space-to-ground-based radar volume matching that occurs in the VN software. The matched spatial and temporal scales (Schwaller and Morris 2011) combined with an intrinsically large number of coincident samples help to firmly establish the degree to which the space-based estimates of the DSD converge with ground-based estimates. This is toward demonstrating attainment of GPM level-1 science requirements that pertain to the DSD.

Acknowledgments. The 2DVD and P2 MC3E, IFloodS, IPHEx, and OLYMPEx field campaign datasets are available through NASA Global Hydrology Resource Center (through https://ghrc.nsstc.nasa.gov/home/fieldcampaigns/XXX, where XXX refers to field campaign). Discussions with Robert Meneghini of NASA Goddard Space Flight Center improved the presentation of the manuscript. Special thanks to all of the 2DVD/P2 and NPOL engineers, technicians, and scientists based at NASA Wallops Flight Facility. This manuscript was funded under NASA Precipitation Measuring Mission NNX16AD45G led by Ramesh Kakar of NASA Headquarters. WAP and DBW acknowledge support from the GPM and PMM programs.

\section{REFERENCES}

Adirosi, E., E. Gorgucci, L. Baldini, and A. Tokay, 2014: Evaluation of gamma raindrop size distribution assumption through comparison of rain rates of measured and radarequivalent gamma DSD. J. Appl. Meteor. Climatol., 53, 1618-1635, https://doi.org/10.1175/JAMC-D-13-0150.1.

, L. Baldini, F. Lombardo, F. Russo, F. Napolitano, E. Volpi, and A. Tokay, 2015: Comparison of different fittings of drop spectra for rainfall retrievals. Adv. Water Resour., 83, 55-67, https://doi.org/10.1016/j.advwatres.2015.05.009.

Andsager, K., K. V. Beard, and N. F. Laird, 1999: Laboratory measurements of axis ratios for large raindrops. J. Atmos. Sci., 56, 2673-2683, https://doi.org/10.1175/1520-0469(1999)056<2673: $\mathrm{LMOARF}>2.0 . \mathrm{CO} ; 2$.

Beard, K. V., and C. Chuang, 1987: A new model for the equilibrium shape of raindrops. J. Atmos. Sci., 44, 1509-1524, https://doi.org/ 10.1175/1520-0469(1987)044<1509:ANMFTE > 2.0.CO;2.

Brandes, E. A., G. Zhang, and J. Vivekanandan, 2002: Experiments in rain estimation with a polarimetric radar in a subtropical environment. J. Appl. Meteor., 41, 674-685, https://doi.org/ 10.1175/1520-0450(2002)041<0674:EIREWA > 2.0.CO;2.

,-- , and -2004 : Drop size distribution retrieval with polarimetric radar: Model and application. J. Appl. Meteor., 43, 461-475, https://doi.org/10.1175/1520-0450(2004)043<0461: DSDRWP $>2.0 . \mathrm{CO} ; 2$.

Bringi, V. N., T. Tang, and V. Chandrasekar, 2004: Evaluation of a new polarimetrically based $Z-R$ relation. J. Atmos. Oceanic Technol., 21, 612-623, https://doi.org/10.1175/1520-0426(2004) 021<0612:EOANPB >2.0.CO;2.

, G. Huang, S. J. Munchak, C. D. Kummerow, D. A. Marks, and D. B. Wolff, 2012: Comparison of drop size distribution parameter (D0) and rain rate from S-band dual-polarized ground radar, TRMM Precipitation Radar (PR), and combined PR-TMI: Two events from Kwajalein Atoll. J. Atmos. Oceanic Technol., 29, 1603-1616, https://doi.org/10.1175/ JTECH-D-11-00153.1.

Cao, Q., G. Zhang, E. Brandes, T. Schuur, A. Ryzhkov, and K. Ikeda, 2008: Analysis of video disdrometer and polarimetric radar data to characterize rain microphysics in Oklahoma.J. Appl. Meteor. Climatol., 47, 2238-2255, https:// doi.org/10.1175/2008JAMC1732.1.

D'Adderio, L. P., G. Vulpiani, F. Porcu, A. Tokay, and R. Meneghini, 2018: Comparison of GPM Core Observatory and ground-based radar retrieval of mass-weighted mean raindrop diameter at midlatitude. J. Hydrometeor., 19, 15831598, https://doi.org/10.1175/JHM-D-18-0002.1.

Duan, Y., A. M. Wilson, and A. P. Barros, 2015: Scoping a field experiment: Error diagnostics of TRMM Precipitation Radar estimates in complex terrain as a basis for IPHEx2014. Hydrol. Earth Syst. Sci., 19, 1501-1520, https://doi.org/10.5194/hess-19-1501-2015.

Gorgucci, E., V. Chandrasekar, V. N. Bringi, and G. Scarchilli, 2002: Estimation of raindrop size distribution parameters from polarimetric radar measurements. J. Atmos. Sci., 59, 2373-2384, https://doi.org/10.1175/1520-0469(2002)059<2373: EORSDP $>2.0 . \mathrm{CO} ; 2$.

Grecu, M., W. S. Olson, S. J. Munchak, S. Ringerud, L. Liao, Z. Haddad, B. Kelley, and S. McLaughlin, 2016: The GPM combined algorithm. J. Atmos. Oceanic Technol., 33, 22252245, https://doi.org/10.1175/JTECH-D-16-0019.1.

Houze, R. A., Jr., and Coauthors, 2017: The Olympic Mountains Experiment (OLYMPEx). Bull. Amer. Meteor. Soc., 98, 21672188, https://doi.org/10.1175/BAMS-D-16-0182.1. 
Iguchi, T., S. Seto, R. Meneghini, N. Yoshida, J. Awaka, M. Le, V. Chandrasekar, and T. Kubota, 2017: GPM/DPR level-2. JAXA Algorithm Theoretical Basis Doc., 68 pp., https:// www.eorc.jaxa.jp/GPM/doc/algorithm/ATBD_DPR_201708_ whole_1.pdf.

Jensen, M. P., and Coauthors, 2016: The Midlatitude Continental Convective Experiment (MC3E). Bull. Amer. Meteor. Soc., 97, 1667-1686, https://doi.org/10.1175/BAMS-D-14-00228.1.

Lee, G., and I. Zawadzki, 2005: Variability of drop size distributions: Time-scale dependence of the variability and its effects on rain estimation. J. Appl. Meteor., 44, 241-255, https://doi.org/ 10.1175/JAM2183.1.

Löffler-Mang, M., and J. Joss, 2000: An optical disdrometer for measuring size and velocity of hydrometeors. J. Atmos. Oceanic Technol., 17, 130-139, https://doi.org/10.1175/15200426(2000)017<0130:AODFMS > 2.0.CO;2.

Park, S. G., H. L. Kim, Y. W. Ham, and S. H. Jung, 2017: Comparative evaluation of the OTT PARSIVEL ${ }^{2}$ using a collocated two-dimensional video disdrometer. J. Atmos. Oceanic Technol., 34, 2059-2082, https://doi.org/10.1175/ JTECH-D-16-0256.1.

Petersen, W. A., P. E. Kirstetter, J. Wang, D. B. Wolff, and A. Tokay, 2020: The GPM Ground Validation program. Satellite Precipitation Measurement, Springer Nature, in press.

Pippitt, J. L., D. B. Wolff, W. Petersen, and D. A. Marks, 2015: Data and operational processing for NASA's GPM Ground Validation program. 37th Conf. on Radar Meteorology, Norman, OK, Amer. Meteor. Soc., 111, https://ams.confex.com/ ams/37RADAR/webprogram/Paper275627.html.

Schönhuber, M., G. Lammer, and W. L. Randeu, 2008: The 2Dvideo disdrometer. Precipitation: Advances in Measurement, Estimation and Prediction, Springer, 3-31.

Schwaller, M., and K. Morris, 2011: Ground validation network for the Global Precipitation Measurement mission. J. Atmos. Oceanic Technol., 28, 301-319, https://doi.org/ 10.1175/2010JTECHA1403.1.

Seliga, T. A., and V. N. Bringi, 1976: Potential use of radar differential reflectivity measurements at orthogonal polarizations for measuring precipitation. J. Appl. Meteor., 15, 69-76, https://doi.org/ 10.1175/1520-0450(1976)015<0069:PUORDR > 2.0.CO;2.

Seo, B.-C., and Coauthors, 2018: Comprehensive evaluation of the IFloodS radar rainfall products for hydrologic applications. J. Hydrometeor., 19, 1793-1813, https://doi.org/10.1175/JHMD-18-0080.1.

Seto, S., T. Iguchi, and T. Oki, 2013: The basic performance of a precipitation retrieval algorithm for the Global Precipitation Measurement mission's single/dual-frequency radar measurements. IEEE Trans. Geosci. Remote Sens., $\mathbf{5 1}$ 5239-5251, https://doi.org/10.1109/TGRS.2012.2231686.

Skofronick-Jackson, G., and Coauthors, 2017: The Global Precipitation Measurement (GPM) mission for science and society. Bull. Amer. Meteor. Soc., 98, 1679-1695, https:// doi.org/10.1175/BAMS-D-15-00306.1.

Thompson, E. J., S. A. Rutledge, B. Dolan, and M. Thurai, 2015: Drop size distributions and radar observations of convective and stratiform rain over the equatorial Indian and west Pacific Oceans. J. Atmos. Sci., 72, 4091-4125, https://doi.org/10.1175/ JAS-D-14-0206.1.

Thurai, M., and V. N. Bringi, 2018: Application of the generalized gamma model to represent the full rain drop size distribution spectra. J. Appl. Meteor. Climatol., 57, 1197-1210, https:// doi.org/10.1175/jamc-d-17-0235.1.

,-- , L. D. Carey, P. Gatlin, E. Schultz, and W. A. Petersen, 2012: Estimating the accuracy of polarimetric radar-based retrievals of drop-size distribution parameters and rain rate: An application of error variance separation using radarderived spatial correlations. J. Hydrometeor., 13, 1066-1079, https://doi.org/10.1175/JHM-D-11-070.1.

Tokay, A., A. Kruger, and W. F. Krajewski, 2001: Comparison of drop size distribution measurements by impact and optical disdrometers. J. Appl. Meteor., 40, 2083-2097, https://doi.org/ 10.1175/1520-0450(2001)040<2083:CODSDM >2.0.CO;2.

,,--- P. A. Kucera, and A. J. Pereira Filho, 2002: Measurements of drop size distribution in the southwestern Amazon basin. J. Geophys. Res., 107, 8052, https://doi.org/ 10.1029/2001JD000355.

_ P. G. Bashor, E. Habib, and T. Kasparis, 2008: Raindrop size distribution measurements in tropical cyclones. Mon. Wea. Rev., 136, 1669-1685, https://doi.org/10.1175/2007MWR2122.1.

_ W. A. Petersen, P. Gatlin, and M. Wingo, 2013: Comparison of raindrop size distribution measurements by collocated disdrometers. J. Atmos. Oceanic Technol., 30, 1672-1690, https://doi.org/10.1175/JTECH-D-12-00163.1.

— L. P. D'Adderio, D. B. Wolff, and W. A. Petersen, 2016: A field study of pixel-scale variability of raindrop size distribution. J. Hydrometeor., 17, 1855-1868, https://doi.org/10.1175/ JHM-D-15-0159.1.

,,--- , and — 2017: A field study of footprint-space variability of raindrop size distribution. J. Hydrometeor., 18, 3165-3179, https://doi.org/10.1175/JHM-D-17-0003.1.

Zagrodnik, J. P., L. McMurdie, and R. A. Houze, 2018: Stratiform precipitation processes in cyclones passing over a coastal mountain range. J. Atmos. Sci., 75, 983-1004, https://doi.org/ 10.1175/JAS-D-17-0168.1. 